CATALAN REVIEW

Catalan Review

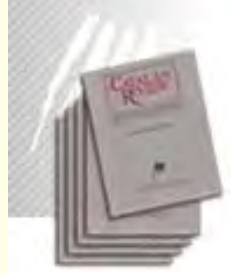

You are accessing the Digital Archive of the Catalan Review Journal.

By accessing and/or using this Digital Archive, you accept and agree to abide by the Terms and Conditions of Use available at http://www.nacs-

catalanstudies.org/catalan_review.html

Catalan Review is the premier international scholarly journal devoted to all aspects of Catalan culture. By Catalan culture is understood all manifestations of intellectual and artistic life produced in the Catalan language or in the geographical areas where Catalan is spoken. Catalan Review has been in publication since 1986 .
NORTH

AMERICAN

CATALAN

SOCIETY
Esteu accedint a l'Arxiu Digital del Catalan Review

A l' accedir i / o utilitzar aquest Arxiu Digital, vostè accepta i es compromet a complir els termes i condicions d'ús disponibles a http://www.nacs-

catalanstudies.org/catalan_review.html

Catalan Review és la primera revista internacional dedicada a tots els aspectes de la cultura catalana. Per la cultura catalana s'entén totes les manifestacions de la vida intel lectual i artística produïda en llengua catalana o en les zones geogràfiques on es parla català. Catalan Review es publica des de 1986.

\title{
Salvador Espriu i la seva «Forma enciclopèdica»: Aspectes d'un sincretisme literari Peter Cocozzella
}

Catalan Review, Vol. VII, number 1 (1993), p. 37-49 


\section{SALVADOR ESPRIU I LA SEVA \\ "FORMA ENCICLOPÈDICA": \\ ASPECTES D'UN SINCRETISME LITERARI}

\section{PETER COCOZZELLA}

Salvador Espriu (1913-1985), narrador i dramaturg català per excellència, ha assolit un reconeixement gairebé universal, dins el domini lingüístic del català no sols entre els erudits sinó també entre el públic en general. Cal esperar que el bon nombre d'estudis fonementals i orientadors ja publicats sobre Espriu, tals com els de Joan Fuster, Joaquim Molas, Maria Aurèlia Capmany, Josep Maria Castellet, contribrueixin a proporcionar al renom de l'autor una ressonància més àmplia cap a la resta del territori espanyol $i$, eventualment, cap a l'estranger.'

Els crítics no es poden estar d'assenyalar la impressionant amplitud i remarcable coherència interna de la visió global espriuana. La producció d'Espriu, veritable encarnació del prototipus que Northrop Frye denomina "forma enciclopèdica», exemplifica admirablement el gènere de màxima envergadura — "un gènere especial», explica Castellet, «el de les grans obres de la humanitat, des de la Bíblia i les grans epopeies fins a Proust i Joyce, passant per La Divina Comèdias (20). La rigorosa anàlisi de Castellet ens mena a descobrir al cor de l'estètica espriuana, una característica essencial que ens convé d'anomenar "sincretisme" - és a dir, l'aptitud genial de l'autor per integrar dins una estructura literària eminentment unitària elements derivats de nombroses i diverses tradicions. Evidentment, Espriu

${ }^{\mathrm{I}}$ Per a una ressenya general de la producció literària d'Espriu, vegeu l'article bibliogràfic de Pijoan Picas, el llibre seminal de Süss i l'estudi biogràfic (Salvador Espriu) de Capmany. Des del 1985 Edicions 62 ha publicar cinc volums de les Obres completes d'Espriu - text que inclou les últimes revisions de l'autor. A la llista següient registrem cada volum amb el seu títol i any de publicació: I (1985), Poesia, $I_{\text {; }}$ II (1987), Poesia, 2; III (1985). Narrativa, I; IV (1989), Narrativa 2; V (1990), Teatre. 
conjumina amb consumada habilior indicis incofusibles d'inspiració bíblica amb al-lusions i referèncias més o menys discernibles a les mitologies antigues (tant grega com egípcia); assimila, tot alhora, preocupacions i procediments típics de la cultura barroca conjuntament amb emanacions cabalístiques gnòstiques i s'exposa, ocasionalment, a influxos de la teologìa negativa i de la "philosophia perennis». ${ }^{2}$

A més a més, com he procurat demostrar en un altre estudi (cf. "Ronda de Mort a Sinera»), l'insigne director de teatre, Ricard Salvat, amb els seus espectaculars muntatges basats en textos d'Espriu, $i$ especialment amb l'escenificació de Ronda de Mort a Sinera (obra estrenada en 1965$)^{3}$ posa de manifest, amb plena esficàcia dels seus recursos dramàtics, els aspectes sobresortints de l'art espriuà, com, per exemple, la mutabilitat proteica de la perspectiva, l'experimentació amb el llenguatge, la varietat dels modes de la mimesi literària, la superposició de distints estrats temporals, la coincidència d'ambients familiars i exòtics, els efectes de desdoblament $\mathrm{i}$ àdhuc de triplicació, la invenció d'una mitologia sui generis —en resum, els nombrosos signes d'aquella propietat que hom, aprofitant la feliç expressió aplicada per Carlos Bousoño a la poesia de Vicente Aleixandre, podria denominar "pupil-la totalitzadora». ${ }^{4}$

${ }^{2}$ Aquí val la pena de cirar l'esmentada conclusió de Casteller sobre els deutes d'Espriu amb la seva tradició: "Del context de la seva [d'Espriu] poesia es desprenen nombroses lectures, influències o afinitats: hem parlat de l'antiguitat egípcia, de la Bíblia i de la mitologia grega, però hauríem d'afegir les religions orientals i Lao-Tsé, la tradició mística jueva, la teologia negativa i la mística cristiana; l'esperit del Barroc, amb la seva "visió tràgica": Racine, Pascal, Gracián i San Juan de la Cruz... I, en menor grau, els grans clàssics catalans, Ramon Llull i Ausiàs March. Espriu se sent hereu espiritual i continuador de tota aquesta tradició. I només si intentem enfocar des d'aquest punt de vista la lectura de la seva obra aconseguirem de vèncer els obstacles previs, moltes vegades posats pel mateix autor" (86).

${ }^{3}$ Ricard Salvat n'ha publicat recentment (' $a n y$ 1985), una edició amb una introducció força orientadora.

4 aLa pupila de nuestro autor, ávida de inmensidades, suele proyectar en un horizonte sin término el objeto particular que un momento ha detenido su atención, porque el poeta comprende en seguida el cariz de parte de un todo que ese objeto incluye, y cómo es a esa totalidad a la que su presencia nos refiere. Aleixandre es así un poeta totalizadorn (Bousoño 94). 
D'acord amb Bousoño, entenem aquella propietat com a factor primordial determinatiu d'un panorama d'innegable abast còsmic. D'altra banda, tot recalcant algunes analogies de l'estètica d'Espriu amb la "cuina literària» $\mathrm{i}$ amb d'altres tècniques integratives del formidable creador de Quixot, Salvat subratlla les arrels hispàniques del sincretisme espriuà ("Salvador Espriu» 226-275).

Així mateix, Joan Fuster (cf. Literatura 333) ens assabenta que, com a símptoma ineludible d'una tendència cosmopolita, compartida amb tot un grup d'autors contemporanis d'edat més avançada - escriptors com Eugeni d'Ors (188I-1954), Joan Puig i Ferrater (1882-1956), Josep Carner (1884-1970), Carles Riba (I893-1959), J. V. Foix (1894-1987), Josep Pla (1897-I98I), Llorenç Villalonga (I897-I980), Joan Oliver (1899-1986) - Salvador Espriu procura mantenir, sense cap inhibició i prejudici, una actitud oberta i receptiva a aquelles manifestacions de la tradició castellana que considera adients al seu tarannà creatiu. En efecte, sense desdir-se de les deus més pregones de la seva inspiració, brollants, com és ben sabut, des del microcosm de la seva estimada Catalunya, Espriu tracta d'evitar, de totes maneres, les limitacions i els horitzonts restringits que, com insistiria el dramaturg suís, Friedrich Dürrenmatt, la literatura "minoritària" d'un Kleinstaat, és a dir, d'una nació petita, ha de metamorfosar, per necessitat de supervivència, en una projecció universalista. ${ }^{5}$ Escriptor d'innegable orientació cosmopolita i universalista, Espriu, per tant, no compromet les seves entranyables aspiracions nacionalistes catalenes, però defuig l'aïllament regionalista de "Catalunya endins" que vicià la literatura prenoucentista al Kleinstaat català de principis del segle xx (cf. Fuster, Literatura 333). Fidel a la peculiar ascendència i ambientació i a d'altres trets de la naturalesa hispànica del seu art, Espriu assoleix, doncs, una contribució importantíssima, pràcticament única en llengua catalana, que testimonieja el pan-hispanisme literari a la mitjana del segle Xx. Diem "pràcticament única" perquè, al cap i a la fi, el

5 Manllevo l'ús d'aquesta terminologia del comentari que en fa George E. Wellwrarth. Dürrenmatt estableix una distinció entre la literatura del Grossmacht ("gran poders) i la susdita del Kleinstaat (Wellwarth I). 
nom d'Agustí Bartra, autor de temperament certament ben distint al d'Espriu, mereix afegir-se al nom d'aquest per tal de designar el "duon català digne del primer rang entre els autors més distingits de la literatura sincrèrica de la nostra època a Espanya $i$ a Llatinoamèrica: Rubén Dario, Juan Ramón Jiménez, Jorge Guillén, Vicente Aleixandre, Pablo Neruda, Jorge Luis Borges, Octavio Paz, entre d'altres. ${ }^{6}$

En funció de l'esmentada "forma enciclopèdica», l'empenta sincretista que inspira tota l'obra espriuana manifesta, repetim, una estructuració d'extraordinària amplada, elaborada amb admirable consistència. Aquesta obra exhibeix, doncs, un plantejament orgànic del qual el mateix Espriu degué tenir plena consciència. Així ho indiquen, per exemple, algunes paraules seves, registrades en el curs de la seva entrevista amb Ignasi Angulo: «No crec que hi hagi una ruptura entre un llibre $\mathrm{i}$ un altre. Tots el meus llibres són cíclics; els uns s'expliquen en funció dels altres; almenys és el que he fet fins ara; no sé si ho he aconseguit, peró aquest és el meu propòsit” (rio). Posant en relleu les declaracions del propi autor, Castellet reconeix que la d'Espriu és una "obra literària en cada una de les etapes de la qual bateguen les etapes posteriors i hi són presents les anteriors» (84).?

${ }^{6}$ Quant a Agustí Bartra vegeu el meu «La veu, la persona i el mite: cap a la definició d'una estètica d'Agustí Bartray.

${ }^{7}$ Vegeu, també, les agudes observacions de Salvat: «Tota l'obra d'Espriu, sigui quin sigui el gènere que emprèn, és el producte, o una diversa revelació d'una mateixa realitat creacional. En Espriu, doncs, cal recordar que la seva obra és un nucli que va llançant cercles concèntrics d'exapansió, que van ampliant-se a mesura que avança l'obra» ( Salvador Espriu» 269). Capmany, també, aprecia l'efecte d'expansió reiterativa, evidenciat en l'obra d'Espriu, que res produeix en un avanç en espiral recollint, a cada nova etapa, no ja sols l'experiència anterior, sinó temes i situacions que són novament, àmpliament i més profundament explicades" (citat en Salvat, "Salvador Espriu" 268).

Aparentment, Espriu va adaptar al seu propòsit aquella fórmula estructural cervantina que Lowry Nelson anomena uincremental repetition" i descriu de la manera següent: "La narrativa principal [de Cervantes] procedeix per repetició incremental..., [és a dir,] en cada episodi alguna nova possibilitat o actualitat és revelada $\mathrm{i}$ afegida al nostre coneixement dels personatges en el món imaginari de Cervantes" (8). Una altra suggestiva analogia i antecedent més proper a la tècnica 
En aquest context trobem particularment digne de citació un paràgraf en què l'estudiosa italiana Giulia Lanciani, mitjançant un judici comprensiu i perspicaç, ens enfronta amb la problemàtica aproximació a la complexitat i profunditat de l'empresa creativa d'Espriu. Partint des de la metàfora de l'espiral, ja emprada per Castellet i Capmany, Lanciani reconeix que en la producció d'Espriu "ogni elemento nuovo della costruzione riprende temi e reflessioni del precedente per puntualizzare i contenuti, sviluppare le implicazioni, approfondirne i significati” (36I). Segueix Lanciani amb algunes consideracions que desvetllen el nostre interès cap a una anàlisi més detinguda:

Un' opera, dunque assenzialmente unitaria, ma anche poliedrica e pluridimensionale in cui lo scavo ermeneutico del critico incontra di continuo insospettate condensazioni e stratificazioni sotterranee ardue da identificare e da connettere tra loro in cui l'unità è il risultato di un costante, puntiglioso ripensamento combinatorio di tessere musive che non di rado sono di provenienza eterogenea. (36I)

Fascinats per aqueixa prodigiosa articulació espriuana entre l'u i el múltiple ressenyada per Lanciani, ens sentim empaitats per la pregunta: Com millor fer-nos càrrec d'aqueixa unitat polièdrica, d'aqueixa

estructural pròpia d'Espriu consisteix en l'«asistemática organicidad" que Blanco Aguinaga percep al llarg de la producció d'Unamuno:

"Esta asistemática "organicidad" hace que ni las ideas ni los sentimientos que expresaba Unamuno estuviesen nunca ordenados y clasificados de antemano para un desarrollo en que cada concepto se apoya en uno anterior, sino que las ideas y los sentimientos se desarrollan en su obra por impulsos e intuiciones, en tangentes muchas veces, dejando indicado aquí lo que en otra parte, y desde otro ángulo, penetraba a fondo. Se crea con ello en su obra un constante ir y venir de ideas, temas, emociones y sugerencias que, porque no se desarrollan plenamente en ningún momento específico, nos obligan a tener siempre presente toda la obra como organismo vivo. El lector de Unomuno habrá observado cómo lo que en un ensayo queda explicado a fondo - o casi a fondo - con la mayoría de sus derivaciones sentimentales y conceptuales, queda en otro ensayo apenas reducido a una palabra, referencia o metáfora, que encierra el eco de lo que en el primer ensayo quedó plenamente elaborado; pero sólo el eco, porque tal vez en este ensayo es otro el tema que persigue Unamunom. (227-8) 
meravellosa orquestració de la inspiració de diverses muses que donen al poeta matèria de reflexió insistent? Si ens llancem a la recerca de fonts específiques, el camí serà ardu i les possibles descobertes no es perfilen gaire animadores. Summament escassos són els indicis clars. És veritat que en comptades ocasions l'escriptor mateix ens deixa declaracions explícites sobre els seus deutes culturals. No hi pot haver dubte sobre la seva filiació amb Valle-Inclán, Unamuno i els altres membres de l'anomenada "Generación del 98". Espriu confessa que "Valle-Inclán es un autor original al que quiero mucho..." (Gubern II6). "De la gent més pròxima a nosaltres", afegeix en una altra ocasió, eha influït en mi indubtablement Valle-Inclán, el dels Esperpentos més que no pas el modernista; l'he tingut molt en compte, encara que no pas d'una manera voluntària. Jo crec que Valle és l'autor dramàtic més important que hi ha hagut a Espanya des del Segle d'Or..." (Angulo i24). Quant a Unamuno i la susdita "Generación", declara: "A pesar de mi evolución en la valoración de Unamuno, pienso dejar sentada mi admiración y respeto por toda la generación del 98. La he leído íntegramente, o casi, y creo que puedo considerarme como un hijo espiritual de ellos. Es mi vinculación literaria que reconozco como más auténtica» (Gubern IIG). Sense pretendre de donar aquí una documentació exhaustiva, arrodonirem aquest context amb una emotiva remembrança d'Espriu: «En Rosselló i jo llegíem aleshores [cap al 1935] els escriptors del noranta-vuit i els modernistes (amb llurs respectius epígons), els quals donaven el to intel-lectual d'aquell moment... (Evocació 23).

${ }^{8}$ Les paraules-clau — «mi evolución en la valoración de Unamuno - impliquen en l'actitud d'Espriu vers el formidable don Miguel una admiració quelcom atenuada, que mostra, a la vegada, un curiós paral-lelisme amb els sentiments de Rosselló-Pòtcel cap al mateix personatge. Espriu ens informa que, en una carta del 6 d'agost de 1934, el dilecte amic Rosselló, després de relacar-li uns contactes personals recents amb el poeta de Salamanca, li manifesta, no amagant la seva exaltació: «ja en sóc més que tu, d'unamunià» (Evocació 27). Peró, en una altra lletra, de l'any següent, el to de Rosselló és ben diferent: "L'Unamuno ha tornat d'Oxford. Avui un diari publica una inteviu amb ell, acompanyada d'una foto: podeu veure don Miguel ajagut damunt el llit. És un home que explota la seva intimitat, àdhuc la personal. No necessitarà mai Eckermann. Ell s'ho fa tot. Com va impressionar-me a Santander! Ha baixaos (citat a Evocació 27). 
Evidentment, a més dels "noventayochistas" hem d'esmentar els modernistes, i tants d'altres antecedentes castellans que, en les paraules de Fuster, "resultarien prou aïllables i de més delicada verificació" (Introducció" XVI). Això no obstant, Fuster pot assegurar-nos que "[e]n els escriptors catalans "del 36 ", és a dir els que pertanyen a la generació d'Espriu, «les lectures castellanes, antigues i modernes es fan notar: Góngora i Guillén, Quevedo i García Lorca, Gracián i Salinas i -Mare de Déu! - la tribu "del Noventa y ocho". Però el perill, aleshores, ja no era greu" ("Introducció" XXV). Seria ociós d'indagar aquí perquè l'il-lustre crític valencià es manté tan recelós per l'espectre d'una possible contaminació atribuible a l'influx d'una literatura forània, tant més perillosa per ser veïna. Ara per ara, tanmteix, ens voldríem anticipar a la perplexitat amb què, com adverteix el mateix Fuster, alguns lectors es miren aquestes fonts castellanes d'Espriu ("Introducción XXV). En efecte, les lectures d'Espriu suara esmentades reflecteixen els trets castellanitzants que són fruits naturals de la posició historicista de l'autor, val a dir de la seva adhesió, com a membre de la Generació del 36 , a la consciència col-lectiva hispànica despertada per la circumstància de la Guerra Civil.

Indicades amb convicció, suposades per deducció o adduïdes hipotèticament, les fonts d'Espriu ens parlen d'una vasta erudició i no solament a l'àmbit de la tradició en llengua castellana. En vista d'aqueixa erudició, no hauria de soprendre'ns que Espriu tingui pocs rivals en els seus coneixements de la literatura catalana de totes les èpoques. Llegint reportatges com la interviu amb Baltasar Porcel (cf., especialment, les pàgs. 393-395) se'ns manifesta la familiaritat d'Espriu amb centenars d'autors paladins dels diversos moviments i corrents literaris posteriors a la Renaixença. I què dir dels clàssics de l'antiguitat? "D'una manera indirecta he tingut en compte els clàs-

9 Segons Joaquim Molas, en les proses poètiques primerenques d'Espriu - específicament, les Petites proses blanques i La pluja, llibres datats respectivament en 1935 1937 i 1936-1938 - hom nota la influència dels autors del 27: "En conjunt, aquests poemes en prosa traduïen la mateixa aventura poètica que les Tres suites ribianes i la Imitació de Rosselló. Ara: com aquest darrer, no pas a través de les especulacions postsimbolistes franceses, sinó de les barroques castellanes de la troupe del 27" (227). 
sics, els quals he llegit força bém, ens contesta Espriu (Angulo I22124). Si preguntem quins són els seus llibres favorits, Espriu pot fer servir la mateixa resposta que va donar a un editor l'any 1952: "Crec que, amb la lectura del Predicador, les Lletres a Lucili, la Divina Comèdia, El Princep, el Discurs del Mètode, el Quixot, el Discreto i alguna novel.la de lladres i serenos, ja en tens ben bé prou per passar, sense crits existencialistes $\mathrm{i}$ altres ineducades expansions, aquesta trista vida" (citat en Capmany I2 $\mathrm{i}$ en Fuster, "Introducción XXIV).

Prou bé sabem nosaltres que les lectures d'Espriu sobrepassen, de bon tros, la llista selectíssima que ens proporciona l'escriptor. Hem de deduir, per això, que aquest tracta d'amagar-nos hàbilment - gelosament?- qualsevol pista que ens podria menar a descobrir els secrets de la seva creació? És inútil fer conjectures sobre un assumpte tan relliscós com el de les intencions d'un artista. Ens cal tenir en compte, més aviat, que en una elaboració literària com la que ens manifesta la producció espriuana, basada en un procediment d'assimilació i d'emulació genial i no d'imitació servil, les fonts es quedaran, naturalment, desdibuixades i transformades $\mathrm{i}$, per tant, sovint serà dificil, si no del tot impossible, de reconèixer-les. Tant se val! Deixem de banda, doncs, qualsevol afany en un intent positivista de trobar fonts específiques -empresa, evidentment, de dubtosa eficàcia en anar dirigida a una meta ben elusiva. Tinguem present, en canvi, que, com ens fa veure Pere Gimferrer, tot fent servir unes parules de Carl Vogel, "[h]i ha una forma d'influència que no és possible de demostrar objectivament pel fet que no és concreta, i que consisteix sobretot en un estímul que sosté allò que ja neix per ell mateix" (20). Reconeguem, a més, la metamorfosi implícita en l'adaptació, per part de la imaginació creativa, de diverses lectures $\mathrm{i}$ inspiracions dins "l'univers creacional d'Espriu — valgui la feliç expressió de Salvat ("Salvador Espriu» 274). Seguirem, en fi, el camí ja obert per Castellet cap al descobriment, dins aqueix "univers», d'una «intel-ligibilitat general", és a dir, en les paraules del mateix crític, cap a la troballa

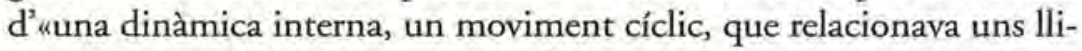
bres amb uns altres i que els englobava en un mateix conjunt" (17). La meta apuntada per Castellet queda ben clara. A la llum de les 
nostres indagacions, estem, ara per ara, disposats a formular un mètode que ens ajudi a assolir-la. Fixem-nos en els punts fonamentals a través dels quals ens serà possible d'atansar-nos a una "intel-ligibilitat generaly, Observem, de primer, que l'estructura global evidenciada en l'obra espriuana es manifesta en funció d'una vastíssima erudició, les fonts de la qual no sempre poden ser destriades amb suficient precisió. L'escassetat de fonts concretes no ens impedeix de constatar, en segon lloc, que aquella estructura global, tot assimilant orgànicament la susdita erudició, troba la seva plena realització virtualment en cadascuna de les obres de l'autor. Examinem, ara, el corol-lari que sorgeix d'aquests dos punts que considerem com a premisses. La visió global d'Espriu exigeix, com a reacció natural de part de l'estudiant o del crític, una perspectiva adient; i aquesta perspectiva, ens cal ara afirmar, s'avé a un enfocament sincrònic. És a dir: no ens pot interessar tant la distinció de diverses etapes que se succeeixen "diacrònicament» en la carrera de l'autor; el que importa es, en realitat, la definició d'un model essencial que es perfila «sincrònicament» al llarg de totes aquelles etapes. ${ }^{\circ}$ Per paradoxal que pugui semblar, el model en qüestió transcendeix l'obra individual $i$, tot alhora, es manifesta inherent a ella. És, en el fons, el "correlatiu ontològic" del sincretisme espriuà, la veritable "epifania" de la successió de les etapes més significatives que configuren l'evolució artistica d'Espriu.

En resum, l'estudi de l'estètica d'Espriu ens confronta amb un repte triple que comporta les tasques següents: assoliment d'una mirada de conjunt; aprehensió d'un model estructural d'abast còsmic; percepció, dins aquell model, de diverses funcions articulades en un joc primordial de simultaneïtat. En vista de l'operació radical d'aquesta dinàmica de simultaneïtat, és oportú dedicar-li uns aclariments preliminars abans d'analitzar-la en detall.

10 Aquest contrast entre el perspectivisme sincrònic i diacrònic en el camp dels estudis literaris correspon a les dues menes d'indagacions ("excursions") — "La transversal y la longitudinal - que Pedro Lain Entralgo distingeix en el camp de la

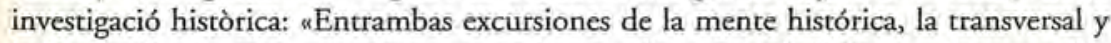
la longitudinal, son enteramente necesarias para "comprender" de veras lo que quiere decir cualquier texto que no exprese realidades objetivas meramente fisicas" (86). 
Fixem-nos, de bell antuvi, que l'estètica espriuana es desenvolupa en un ambient caracteritzat per una remarcable flexibilitat formal. Aquest context proteïforme emana, en part, si més no, des d'un rebuig radical de les categories tradicionals. El mateix Espriu minimitza la significança de les línies divisòries, establertes a base d'una classificació genètica. "[J]o no crec gaire en els gèneres literaris", confessa durant l'entrevista amb Angulo. I continua, tot seguit: "sobretot en la meva literatura, crec que es tracta de vasos comunicants, es passa de la meva lírica a la narrativa i de la narrativa al teatre i del teatre a la lírica sense solució de continuïtat, de fets. (124). L'acte creatiu d'Espriu, s'efectua, aleshores, en paratges oberts i indefinibles, és a dir en diversos àmbits mentals i psíquics, cadascun dels quals podríem identificat amb un "estat" o un "moden de creativitat. Espriu, per això, explota al màxim la naturalesa de la imaginació poètica, lliure de limitacions, impediments i contingències temporals o materials. I, d'acord amb aqueixa naturalesa, els susdits àmbits amb llurs modalitats corresponents es compenetren amb la variabilitat instantània, pròpia dels estats psíquics i mentals.

En una altra ocasió, he procurat il-lustrar aquesta propietat de variabilitat o volubilitat, que també es podria anomenar alternància sobtada o simultània, mitjançant la metàfora de dos esferes concèntriques que enclouen àrees diferents si bé complementàries (cf. Cocozzella, «Introspection" 260-26I). La primera esfera simbolitza, en un moviment centrífug sempre més expansiu, l'afany de comunicació de la persona de l'autor amb els altres éssers humans o amb l'univers en general. La segona esfera exemplifica, en canvi, amb una gravitació centrípeta, la concentració, cada vegada més intensiva al voltant d'un nucli irreductible -el món interior de la mateixa persona.

Prenguem en compte, doncs, aquestes característiques primordials de volubilitat, sincronisme i sincretisme. Una ressenya, per sumària que sigui, de la producció d'Espriu ens comprovarà que la confluència dels gèneres - "vasos comunicants", com ens declara, metaforicament, el mateix poeta - la forma proteica, l'alternança, sorprenent per inesperada, des d'una modalitat literària a una altra, la correspondència harmònica i simultània entre dues esferes - la cen- 
tífuga i la centrípeta- que il.lustren la creativitat de l'autor són símptomes d'una intuició genial. Gradualment, ens adonarem que el que Espriu intueix és un equilibri suprem en l'univers - o sigui, una complementaritat transcendent entre els éssers del cosmos a despit de totes les manifestacions de contrarietats, lluites i cacofonies. Això no vol dir, naturalment, que Espriu s’aferri a una visió color de rosa de la realitat. Fuster (cf., per exemple, "Introducció" XXVIII-XXX) i tants d'altres han parlat, amb raó, del pessimisme espriuà. Aqueixa foscor, així i tot, no exclou la possibilitat d'un raig d'esperança i el somni d'una redempció, encara que projectada en un paradís que, a vegades, sembla irremeiablement perdut. Recordem, de passada, els versos memorables — «Parlo d'esperança, / desesperançat»- dins el poema XVI del Llibre de Sinera (1963), que expressen admirablement una disposició d'ànim digna, per cert, de la nostra consideració.

No sols el pessimisme sinó també l'esperança condicionen, en línies generals "d'alternança sobtada" típica de l'ambientació evocada a l'obra d'Espriu. El vaivé constant de la foscor a la llum — «[d]e la llum a la fosca, / de la nit a la neu", segons el que ens comunica la veu personificada al poema XXX de Final del laberint (1955) reflecteix una consciència poètica que, en un estat de plena maduresa, s'aboca a la realitat circumdant, tot reaccionant vitalment amb ella. Guia suprema per a la persona poètica en el seu Weltanschauung, val a dir, en la seva concentració meditabunda i en el seu arrelar-se existencialment en el cosmos, és l'extraordinària sensibilitat històrica $o$, en les paraules de Castellet el "pathos històric" d'aquella persona (I4).

El tarannà global, "enciclopèdic" de l'art espriuà recolza en dos filons: l'historicista $\mathrm{i}$ un altre relacionat amb un plantejament distintiu de la modalitat tràgica. Ara per ara, no ens convé d'emprendre una anàlisi d'aquests dos aspectes parcials, que ens menaria a sortir del tema del present assaig. Hem de deixar, per tant, per una altra ocasió, l'estudi de l'historicisme i la visió tràgica de Salvador Espriu. 


\section{REFERENCIES}

ANGULO, Ignasi. Entrevista amb Salvador Espriu. [Dades de publicació inassequibles.]

Blanco Aguinaga, Carlos. El Unamuno contemplativo. México: Fondo de Cultura Económica, 1959.

Bousoño, Carlos. La poesía de Vicente Aleixandre. Madrid: Gredos, 1956.

CAPMANY, Maria Aurèlia, Salvador Espriu. Barcelona: DOPESA, 1972.

Castellet, J. M. Iniciació a la poesia de Salvador Espriu. Llibres a l'Abast Ioo. Barcelona: Edicions 62, 1971.

Cocozzella, Peter. «La veu, la persona i el mite: cap a la definició d'una estètica d'Agustí Bartran. Rasico i Wittlin 245-65.

- "Recollection and Introspection in Salvador Espriu's Cementiri de Sineras. Gulsoy i Solà-Solé 259-265.

- "Ronda de Mort a Sinera: An Approach to Salvador Espriu's Aesthetics". Duran et al. 307-330.

Duran, Manuel, Albert Porqueras-Mayo i Josep Roca-Pons, eds, Actes del Segon Col.loqui d'Estudis Catalans a Nord-America (Yale, I979). Montserrat: Publicacions de l'Abadia de Montserrat, I982. ESPRIU, Salvador. Evocacions de Rosselló-Pòrcel $i$ altres notes. Barcelona: Joaquim Horta, 1957.

-. Obres completes. 5 vols. Ed. Francesc Vallverdú. Barcelona: Edicions 62, 1985-1990.

FRYE, Northrop. Anatomy of Criticism: Four Essays. 1957. New York: Atheneum, 1969.

FUSTER, Joan. "Introducció a la poesia de Salvador Espriu». Obra poètica. Per Salvador Espriu. Barcelona: Santiago Alberti, 1963. XIII-LXXII.

- Literatura catalana comtemporània. Barcelona: Curial, 1972.

Gimferrer, Pere. Antoni Tàpies i l'esperit català. Barcelona: Edicions Polígrafa, S. A., s. d.

Gubern, Román. Entrevista con Salvador Espriu. Primer Acto 60 (1965): 13-7.

GulsoY, Josep i Josep M. Solà-Solé, eds. Catalan Studies (Estudis so- 
bre el català): Volume in Memory of Josephine De Boer. Colección Lacetania 4. Barcelona: Hispam, 1977.

Laín Entralgo, Pedro. Desde la "Polémica de la Ciencia Española" hasta la Generación del 98. Madrid: Aguilar, 1956. Vol. I de España como problema. 2 vols.

LANCIANI, Giulia. "Salvador Espriu: da Les cançons d'Ariadna a Setmana Santar. Estudis Universitaris Catalans 23 (1979): 361-372.

MolaS, Joaquim. "La poesia de Salvador Espriu». Serra d'Or 6 (1964): 227-230.

Nelson, Lowry, Jr., ed. Cervantes: A Collection of Critical Essays.

Englewood Cliffs, N. J.: Prentice-Hall, 1969.

PIJOAN PICAS, Maria Isabel. «Selección bibliográfica de Salvador

Espriu". Nuevo Hispanismo 2 (1982): 233-49.

PORCEL, Baltasar. "Salvador Espriu, foc i cendra». Serra d'Or 8 (1966): 387-395.

Rasico Philip D. i CurT J. Wittlin, eds. Actes del Cinquè Col.loqui d'Estudis Catalans a Nord-Amèrica (Tampa-St. Augustine,1987.) Montserrat: Publicacions de l'Abadia de Montserrat, 1989 .

SALVAT, Ricard. Introducció [ «Per a una història de Ronda de mort a Sinera (1965-1985)"]. Ronda de mort a Sinera. Per Salvador Espriu/Ricard Salvat. Barcelona: Editorial Empúries, 1985. 7-32.

-. "Salvador Espriu". El teatre és una arma? Barcelona: Ediciones 62, 1966. 266-75. Vol. I de El teatre contemporani, 2 vols, 1966.

Suss, Kurt. Untersuchungen zum Gedichtwerk Salvador Esprius, Nürnberg: Verlag Hans Carl, 1978.

WellWARTH, George E. Introduction. 3 Catalan Dramatists. Ed. George E. Wellwarth. Montreal: Engendra Press, 1976. I-7. 